\title{
THE PHYSIOLOGIC ACTION OF HISTAMINE APPLIED DIRECTLY TO THE SEROSA OR MUCOSA OF SMALL INTESTINE OF THE GUINEA PIG
}

\author{
YASUKAZU TERADA \\ Department of Pharmacology, Mie Prefectural University School of Medicine, Tsu \\ Received for publication July 2, 1956
}

\section{INTRODUCTION}

It is well known that the small intestine of the guinea pig is extremely sensitive to histamine (1-3), so the author took advantage of this nature to determine the quantity of the minute histamine (4) or to examine the virtue of antihistaminics (5). But the subject in question is the physiologic action of histamine applied directly to the serosa of the small intestine, and not that of histamine applied to its mucosa. Hitherto we have understood that the physiologic action of medicament applied directly to the serosa of intestine is the same as in the case of mucosa, unless any impediment appears. But the case is not true with action of histamine, because the serosa of small intestine is reactive physiologically in extremely small concentrations [even in $1: 2,000,000,000$ solution of histamine (4)], but very large oral doses (300 $\mathrm{mg}$ ) are tolerated without toxic effects (6), and histamine is said to be stable in alimentary canals of animals (7), and also histaminase is said not to be in existence in the mucosa of small intestine of the guinea pig (8). Therefore it is concluded that the enteric mucosa of guinea pig does not show any reaction to histamine and so report some people (9-11). But Kendall (12) says that histamine dichloride solutions applied either fail to induce contractions, or incite them, if any, very slow and limited to the enteric mucosa; only its neutral solutions (free base) usually induce slow but progressive contractions after a latent period of 30 to 60 seconds. If his report is reliable, histamine in its neutral or free base induces contractions to intestine. Histamine dichloride by oral administration must, in his opinion, become free base in the small intestinal canal $(\mathrm{pH} 8.0)$ to induce contractions with the result of diarrhea, but in fact it is taken without toxic effects $(6,13)$. Thus the problem has not been exactly explained by any one for many years. For explanation of this problem, at first, a new apparatus should be found to apply the medicament directly to enteric mucosa. Fortunately the author has contrived this new apparatus and studied the action of histamine on mucosa, which the author is to report here by. Still more, its action on enteric serosa has also been studied as control. 
I. The physiologic action of histamine applied directly to the serosa of the small intestine

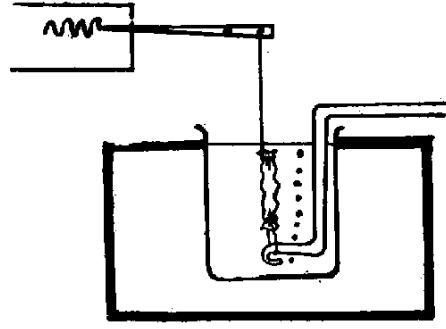

FIG. 1. Illustration of the modified Magnus' method.

\section{METHODS}

By Magnus' method, a piece of small intestine isolated from a guinea pig is suspended in beaker containing $50 \mathrm{cc}$ of Tyrode solution $\left(37^{\circ} \mathrm{C}\right)$ with thread leading to a Gohara's recording lever and its peristalsis is recorded on a smoked drum (Fig. 1), and then suitable quantity of histamine dichloride (made in Wako Junyaku Co., Japan) is poured into the beaker.

\section{RESULTS}

As in Fig. 2, Icc of $1: 1,000,000$ solution of histamine ( $1: 50,000,000$ in beaker) induces the enteric contraction a little, and with cumulation of $1 \mathrm{cc}$ of its $1: 100,000$ solution the contraction greatly increases rapidly, but when we add another $1 \mathrm{cc}$ of its $\mathrm{I}: 10,000$ solution, this time, a little relaxation appears, and with another $1 \mathrm{cc}$ of its $1: 1,000$ solution the relaxation becomes stronger. Next, as in Fig. 3, with lcc of
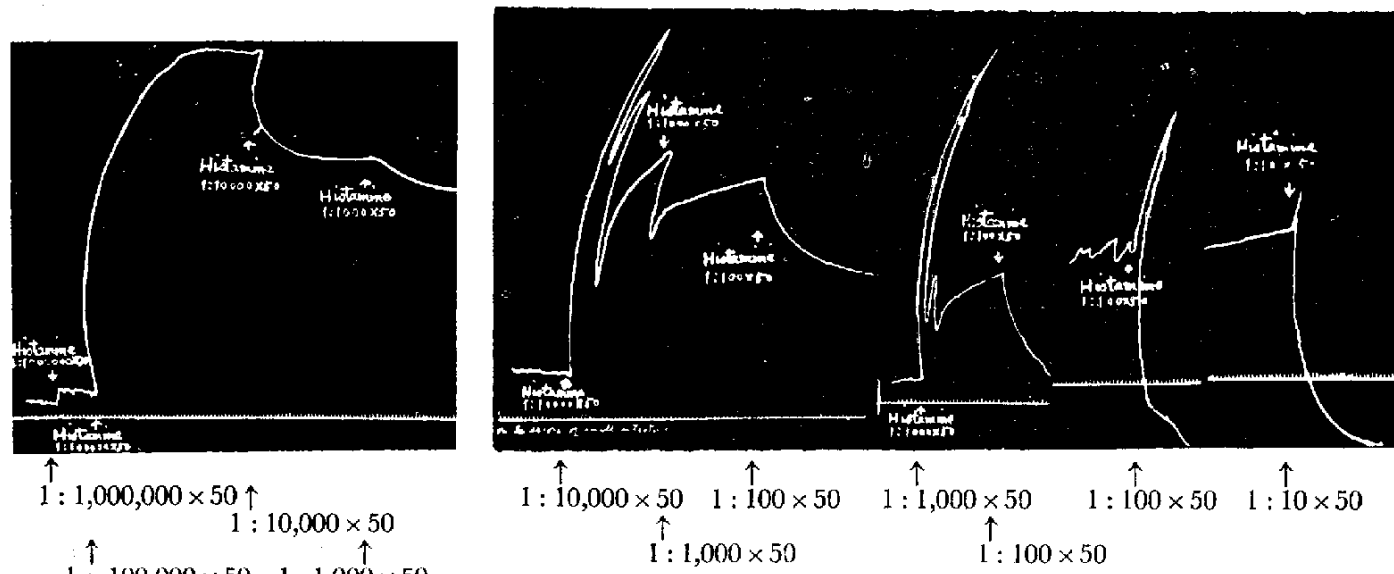

FIG. 3. Physiologic action of histamine dichloride applied directly to the serosa of small intestine of the guinea pig (2). histamine dichloride serosa of small intestine of the guinea pig (1).

its $1: 10,000$ solution $(1: 500,000$ in beaker), a new enteric piece is contracted powerfully without delay and soon relaxed medially, then with $1: 1,000$ solution ( $1: 50,000$ in beaker), it is contracted powerfully and soon relaxed again to the original degree of tension, with $1: 100$ solution (1:5,000 in beaker), it contracted a little and soon relaxed to become a longer than what it originally was, and at last with $1: 10$ solution ( $1: 500$ in beaker), it contracted very little and greatly relaxed. But the certain transition concentration of histamine from contraction to relaxation of small intestine is not found from these six kinds of solutions. The reason 
is unknown, but it may be to the season (generally, in summer, the intestine is very sensitive to histamine, but in winter, insensitive). These actions appear immediately after administration and have no latent periods.

\section{II. 'The physiologic action of histamine applied directly to the mucosa of small intestine}

\section{METHODS}

In vitro experiment, as in Fig. 4, two curved glass-tubes are inserted in beaker containing 300 cc of Tyrode solution, and two ends of isolated, surviving intestinal strip from guinea pig are bound to each one end of two glass-tubes, and other cnd of a glass-tube is connected to a Mariotte bottle with gummy tube, and other end of another glasstube is connected to a funnel with gummy tube. Then the fluid in the Mariotte bottle (Tyrode solution or water) flow out funnel through the gummy tubes, glass-tubes and intestinal canal under

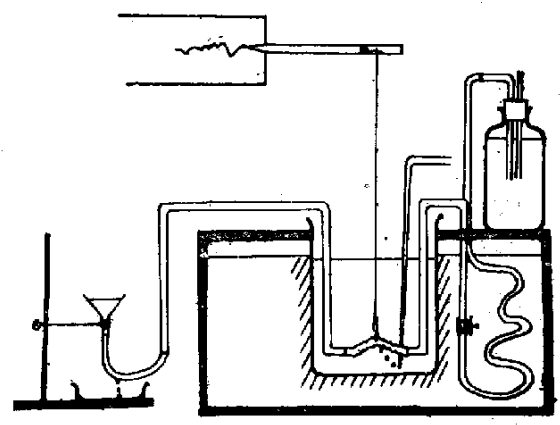

Fig, 4. Apparatus for the application of solutions directly to the mucosa of survived intestine. constant pressure. Thus by holding up the funnel the pressure of intestinal canal is increased, or by tightening a pinchcock attached to gummy tube on the Mariotte bottle side, the flow of water decreases and the pressure of intestinal canal is also decreased. In this apparatus, the intestinal inner pressure is lowered to as little as possible, and an intestinal piece is relaxed to draw a bell-shaped curve, and a thread attached to the middle of the piece, and to a recording lever, which writes on a smoked drum, makes the recording device. The medicament is injected into gummy tube as near as possible to the piece on Mariotte bottle side. By the pressure due to injection the enteric peristalsis changes a little, but recovers within 1 minute. While the action of histamine appears powerfully in most cases after latent period of about 1 minute, changes due to pressure of medicament become no obstructions. Next, if a red ink is injected in place of medicament, it gets into intestinal piece in a moment, but it takes some times before the ink passes through the enteric canal and flow out funnel, because the piece is situated on the bottom of "U"-tube in this apparatus. If histamine moves as similarly as red ink, its action must take place during that period. Following this idea, we adjusted this apparatus to let histamine flow as slowly as possible (to let it take about 10 minutes, before it flow out completely). The Tyrode solution must contain enough air and be kept warm at $37-38^{\circ} \mathrm{C}$ with thermostat. In vivo experiment, the guinea pig narcotized with urethane is put in Tyrode bath warmed with thermostat, with its abdomen open, and both sides of a free strip of small intestine (ileum ?) of suitable length are bound to each end of two glass-tubes as in vitro, and the same technic as in vitro is repeated, so the fluid in bottle flows through this strip of intêstine circulated with blood. This fluid may be Tyrode solution or water in vitro, but the author has used Tyrode solution in viwo, because, if water is used in vivo, the blood infiltrates into the intestinal canal. 


\section{RESULTS}

a) Results in vitro. As in Table 1 and Fig. 5, $1 \mathrm{cc}$ of $\mathrm{I}: 1,000,000$ and $1: 100,000$ solutions of histamine seems to have no effect on intestinal strip, but $1 \mathrm{cc}$ of its $1: 10,000$ solution induces a little contraction in a few cases, and $1 \mathrm{cc}$ of $1: 1,000$ solution brings remarkable and powerful contraction in most cases. In these cases, the piece forming the bell-shaped curve becomes straight in line and it seems to have maximum contraction, causing the temporary stop of flow. Then the piece begins to recover again, and after about 10 minutes it recovers completely, though the time is effected by the quantity of histamine and speed of the flow, whichever part of intestine we may use. But the most important thing is that the season of the year affects the experiment, so even 1:100 solution gave no effect to intestine (Table 1), because in winter its sensitivity to histamine is very little, and with one exception, $1: 100$ solution has no effect to the strip after the administration of $1: 1,000$ solution (Fig. 5).
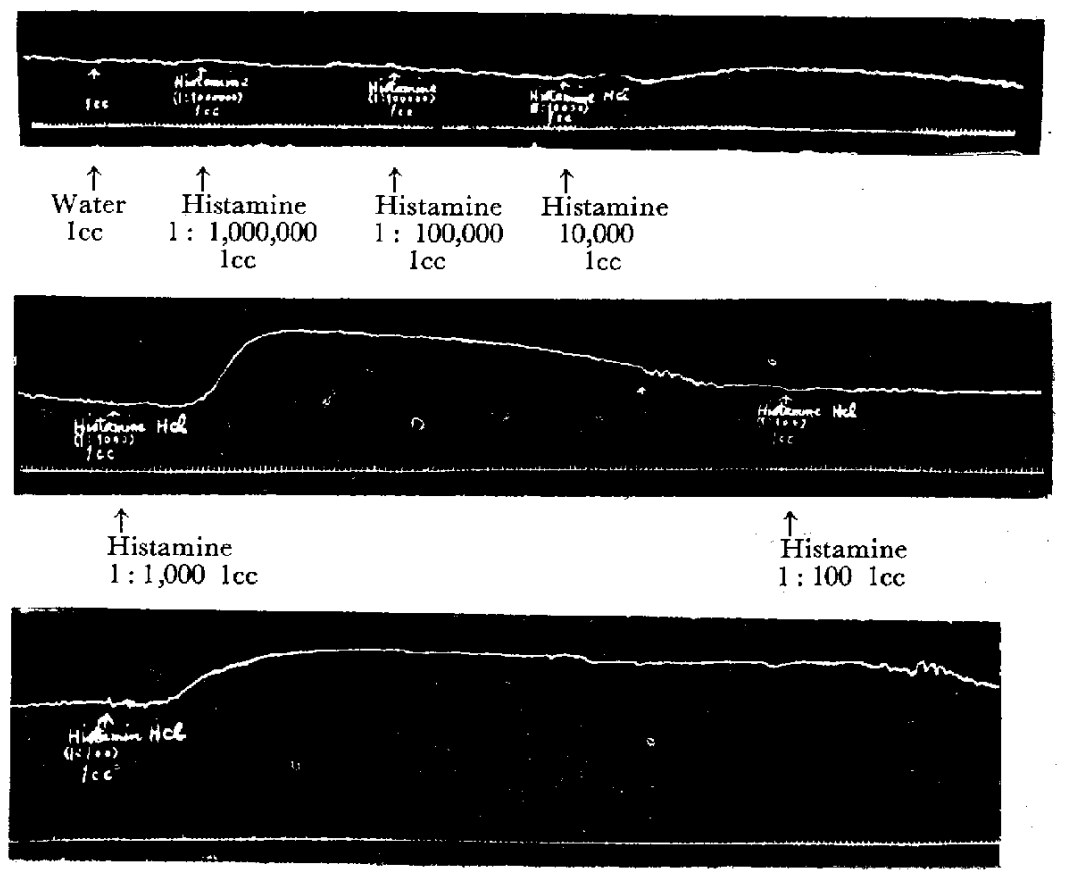

$\uparrow$

Histamine

1: $100 \mathrm{Icc}$

FIG. 5. Physiologic action of histamine dichloride applied directly to the mucosa of small intestine of the guinea pig (in vitro).

b) Results in vivo. In vivo, as in Table 1 and Fig. 6, a feeble contraction may be observed in $1 \mathrm{cc}$ of $1: 100,000$ solution of histamine in a few cases, but the action begins to take place definitely at lcc of $1: 1,000$ solution (Table 1), and some certain action can be observed in $1: 100$ solution. Therefore the action in vivo is weaker than that in vitro, and in both experiments appear only the contractions and no relaxations. 
TABLE 1. Physiologic action of histamine dichloride on the mucosa of small intestine of the guinea pig.

\begin{tabular}{|c|c|c|c|c|c|c|c|}
\hline \multicolumn{2}{|c|}{$\begin{array}{c}\text { Dose of } \\
\text { histamine }\end{array}$} & $\begin{array}{c}1: 1,000,000 \\
1 \mathrm{cc}\end{array}$ & $\begin{array}{c}1: 100,000 \\
1 \mathrm{cc}\end{array}$ & $\begin{array}{c}1: 10,000 \\
1 \mathrm{cc},\end{array}$ & $\begin{array}{c}1: 1,000 \\
1: \mathrm{cc}\end{array}$ & $\begin{array}{l}1: 100 \\
1 \mathrm{cc}\end{array}$ & $\begin{array}{l}1: 10 \\
1 \mathrm{cc}\end{array}$ \\
\hline \multirow{2}{*}{ 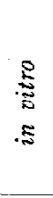 } & Contraction $\left\{\begin{array}{l}\text { strong } \\
\text { feeble }\end{array}\right.$ & $\begin{array}{l}0 \\
0 \\
\end{array}$ & $\begin{array}{l}0 \\
0 . \\
-\cdots\end{array}$ & $\begin{array}{l}0 \\
3\end{array}$ & $\begin{array}{l}9 \\
0\end{array}$ & $\begin{array}{l}5 \\
0\end{array}$ & $\begin{array}{l}4 \\
4\end{array}$ \\
\hline & $\begin{array}{l}\text { No effect } \\
\text { Relaxation }\end{array}$ & $\begin{array}{l}2 \\
0\end{array}$ & $\begin{array}{l}5 \\
0\end{array}$ & $\begin{array}{l}5 \\
0\end{array}$ & $\begin{array}{c}(3 ?) \\
0\end{array}$ & $\begin{array}{l}(3 ?) \\
0\end{array}$ & $\begin{array}{l}0 \\
0\end{array}$ \\
\hline \multirow{2}{*}{ 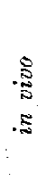 } & Contraction $\begin{array}{c}\text { strong } \\
\text { feeble }\end{array}$ & $\begin{array}{l}0 \\
0\end{array}$ & $\begin{array}{l}0 \\
1\end{array}$ & $\begin{array}{l}0 \\
1\end{array}$ & $\begin{array}{l}3 \\
2\end{array}$ & $\begin{array}{l}8 \\
1\end{array}$ & $\begin{array}{l}5 \\
0\end{array}$ \\
\hline & $\begin{array}{l}\text { No effect } \\
\text { Relaxation }\end{array}$ & $\begin{array}{l}1 \\
0\end{array}$ & $\begin{array}{l}3 \\
0\end{array}$ & $\begin{array}{l}6 \\
0\end{array}$ & $\begin{array}{l}3 \\
0\end{array}$ & $\begin{array}{l}0 \\
0\end{array}$ & $\begin{array}{l}0 \\
0\end{array}$ \\
\hline
\end{tabular}

The number indicates the case of experiment.

c) Tachyphylaxis of the mucosa of small intestine to histamine. In vivo, as in above results, $1 \mathrm{cc}$ of $1: 10$ solution of histamine induces the contraction of intestinal strip powerfully. But the same dose, after recovery or on its way to recovery, induces the same contraction no more (Fig. 7). In vitro, too, one of the same cases appeared only once (Fig. 5).
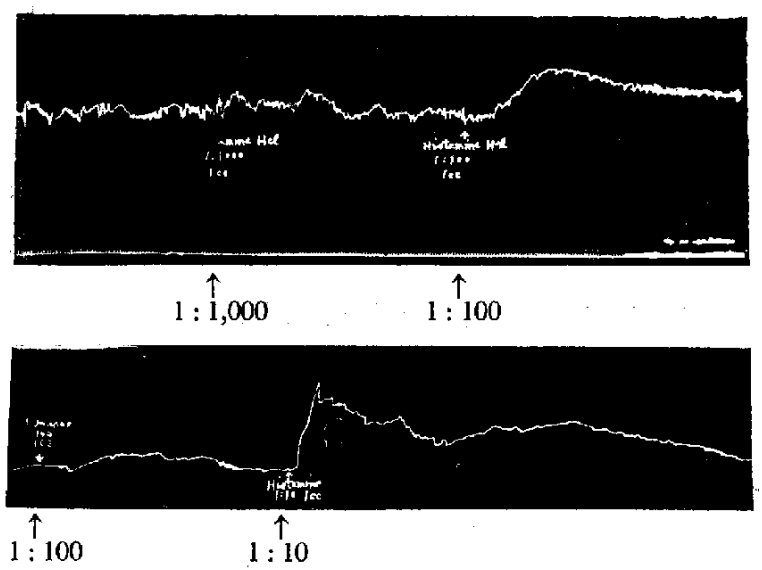

FIG. 6. Physiologic action of histamine dichloride applied directly to the mucosa of small intestine of the guinea pig (in vivo).

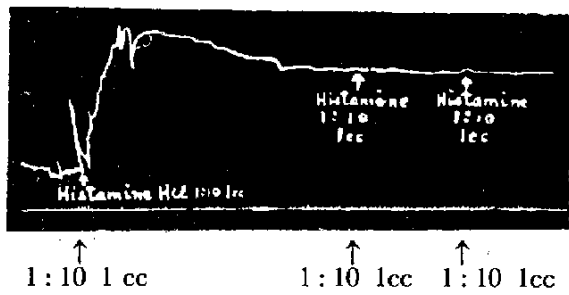

FIG. 7. Tachyphylactic reaction of the mucosa of small intestine of the guinea pig to histamine dichloride.

Thus the enteric mucosa seems to acquire a tachyphylaxis to concentrated solution of histamine.

d) The action of histamine of free base or its dichloride on the mucosa of small intestine. As in Fig. 8, $1 \mathrm{cc}$ of $1: 1,000$ solution of histamine brought to $\mathrm{pH} 8.0$ with $\mathrm{NaOH}$ which is used to change histamine into that of free base, when injected into the stream of water through its canal in vitro, induces the intestinal contraction powerfully, though it becomes more neutral. 
After its recovery or in case of fresh canal, the same dose of histamine dichloride brings the same result (Fig. 8).

The $1: 1,000$ solution of histamine dichloride is 5.0 in $\mathrm{pH}$, the $\mathrm{pH}$ of one part of this acid salt dissolved in 100 parts of water is brought to only 6.0. In this apparatus, the water held in glassand gummy tubes from injected point to intestinal strip is only $4 \mathrm{cc}$ in volume, so this acid salt is diluted only 4 times, after injection of $1 \mathrm{cc}$ of $1: 1,000$ solution. Therefore the acid salt itself, which has not been diluted to more than 100 times even in- or out-flow is taken into account, seems to be surely applied to enteric mucosa.

Thus judging from the above results, the action of its free base is just the same as that of its acid salt.

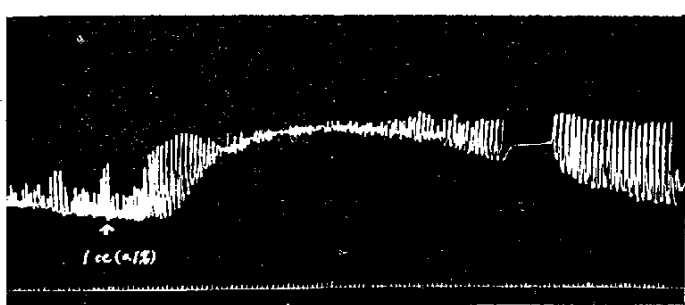

$\uparrow$ Free base of histamine $1: 1,0001 \mathrm{cc}$

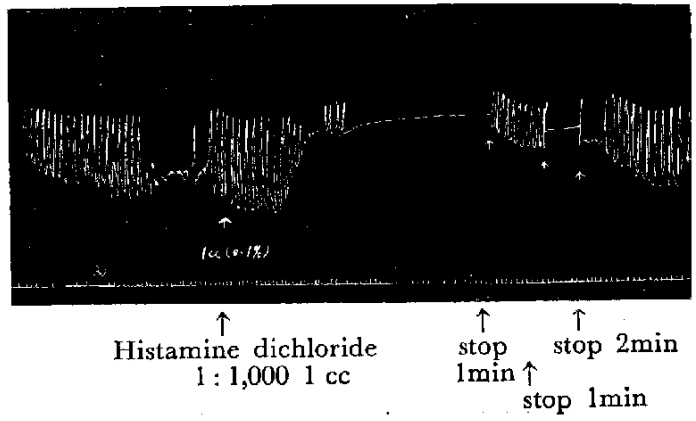

FIG. 8. Physiologic action of the free base and dichloride salt of histamine on the mucosa of small intestine of the guinea pig (in vitro).

e) The latent period of action of histamine applied directly to the mucosa of small intestinal strip. When histamine solutions are applied through gummy tube directly to mucosa of intestinal strip, both in vivo and in vitro, its action appcars not just after but after a certain latent period in most cases, as in Table 2, either in direct or inverse proportion to its concentrations. As shown in the serics of experiments, the individuality and speed of the stream are out of the question, but a time for the solution to reach the intestinal canal must be considered, and so it is important that 90-30 seconds in most cases should exist as its latent period.

TABLE 2. Time lag of action of histamine applied directly to the mucosa of small intestine of the guinea pig.

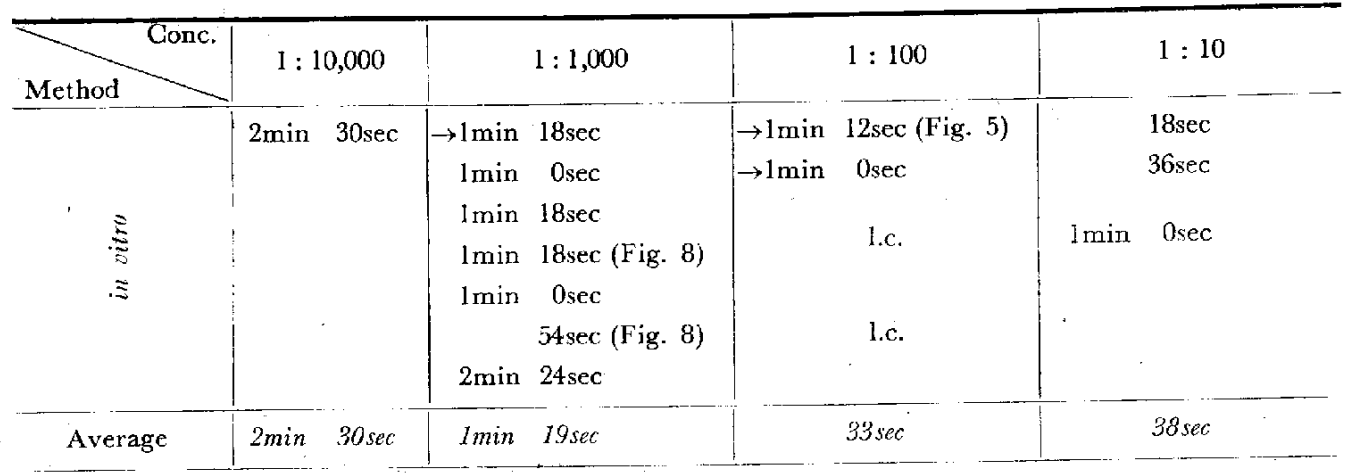




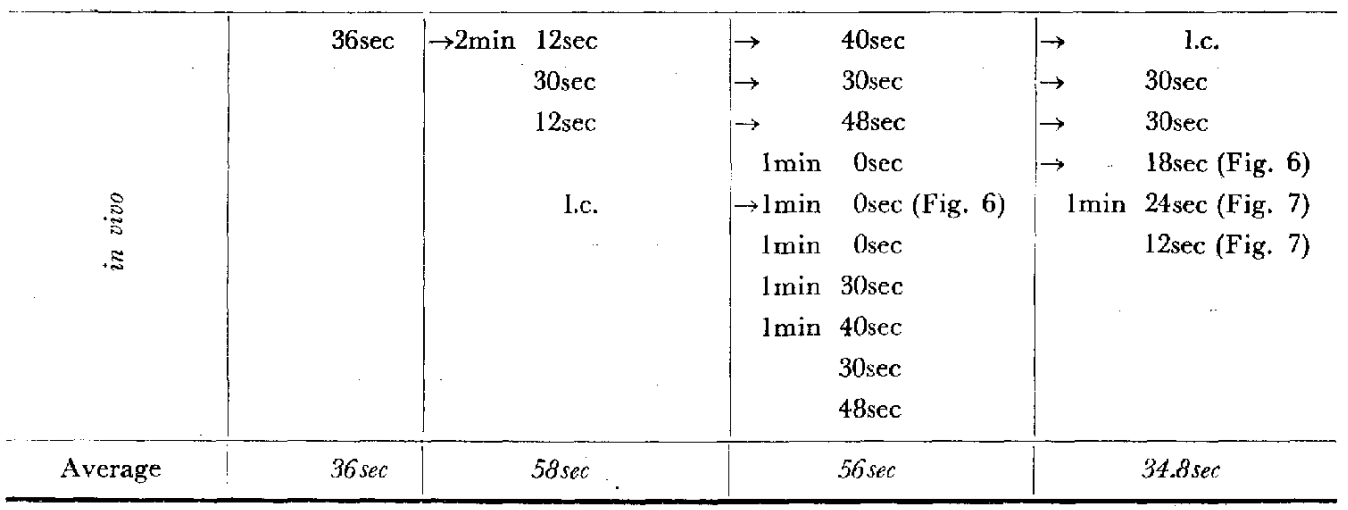

Arrow indicates the serial experiment.

\section{DISGUSSION}

From above results it is confirmed that the dilute solution of histamine applied directly to the serosa of isolated, surviving small intestinal strip induces contraction, while the concentrated one induces relaxation, as in Nishiyama's report (3); therefore it seems that histamine has two factors of contraction and relaxation acted on the small intestine. In another way, histamine solutions applied directly to its mucosa induce contractions alone and no relaxations, and its concentrated solution brings tachyphylaxis of its mucosa. The action of histamine to the enteric serosa appears rapidly, while the action to its mucosa generally slowly (90-30 scconds as latent period). In this apparatus for experiment on mucosa, the medicament goes considerably fast to intestinal strip, while the action appears slowly. This conflict may be construed as indicating that the absorption through the mucosa is a relatively slow process, and that effect is on the underlying smooth muscle, as in Kendall's report. Why, then, in a few cases, the contractions appear without delay or after a short time (Table 2)? As this problem cannot be explained in any way in this experiment, the author cannot wholly support Kendall's theory.

Thus the action are not same in the case of histamine on the serosa as in that on the mucosa.

Next, what is the estimate of concentration of histamine applied to mucosa? This could not be estimated in this apparatus, but a higher concentration of histamine must be necessary to induce intestinal contraction to mucosa than to serosa (only $1 \mathrm{cc}$ of $1: 100$ solution through intestinal canal just induces certain contractions to mucosa in vivo, which even 20 billion times solution can barely do in case of serosa), and so some substances to inhibit the action of histamine may perhaps exist anywhere in mucosa. These may be a reason why histamine cannot induce diarrhea to any animal in oral way.

Next, the mucosa of small intestine is less sensitive to histamine in viro than in vitro. This may be due to the fact that a little quantity of histamine is probably carried away in blood stream in vivo.

The action of histamine dichloride is the same as that of its free base to the contrary of Kendall's report as well as of Rentz's, and the author cannot explain this fact. 
The fluid streaming through intestinal canal, whether water or Tyrode solution, does not affect the action of histamine. It is very interesting to know that the base of histamine and $\mathrm{pH}$ of fluid streaming through intestinal canal in this experiments do not disturb the action of histamine applied to the mucosa of small intestine.

\section{SUMMARY}

1. Dilute histamine solutions, applied directly to the serosa of isolated, surviving small intestinal strip of guinea pig induce contractions, while its concentrated ones induce relaxations, without any latent period.

2. Histamine solutions applied directly to enteric mucosa of guinea pig induce only contractions after a latent period (90-30 seconds).

3. The small intestinal mucosa of guinea pig acquires tachyphylaxis to concentrated solutions.

4. It is clear from these results that the action of histamine applied directly to enteric serosa of guinea pig is different from that of histamine applied directly to its mucosa.

5. In above experiment, the base of histamine and $\mathrm{pH}$ of fluid streaming through intestinal canal do not disturb the action of histamine applied to enteric mucosa.

Acknowledgement. In closing, the author wish to thank Prof. Z. Kanda of Nagoya University for his advice given to this experiments.

\section{REFERENCES}

1) FukutA, T.: Psychiat. et Neurol. Japon. 42, 642 (1938)

2) Fukuta, T.: Report of Jap. Scient. Soc. 16, 139 (1942)

3) NishiYAMA, I.: Folia pharmacol. japon. 29, $97 \$$ (1940)

4) AkiYama, Y.: Fukuoka Acta Med. 30, 1, 42, 59 \& 80 (1937)

5) BROWN AND WERNER: $J$. Allergy 19, 325 (1948)

6) SollmanN, T. : A Manual of Pharmacology Ed. 7, P. 407 (1950)

7) POPIELSKI, L.: Fflügers Atch. 178, 214 (1920)

8) Tachikawa, K. and Nakajima, S.: Osaka Med.J. 5, No. 8, 1 (1934)

9) Rentz, E.: Arch. exp. Path. Pharmak. 191, 183 (1938)

10) MEAKins, J. AND HaRringtoN, R.: J. Pharmacol. 18, 455 (1921); 20, 45 (1922)

11) KOESSLER AND HANKE: J. biol. Ghem. 59, 889 (1924)

12) Kendalt, I. AND VARNEY, P.I..: $J$. infect. Dis, 41, 143 (1927)

13) Georg, F.: Wien. Arch. inn. Med. 20, 287 (1930) 